\title{
Análisis y Diseño de Sistemas de Gestión Electrónica de Documentación en Grandes Entidades
}

\section{Arturo Camarero González}

Consultor. Innovación en Archivos y Documentación, S.A.

\subsection{Resumen}

La implantación con éxito de soluciones basadas en Sistemas de Gestión Electrónica de Documentación (SGED) requiere su diseño previo en base a una Metodología que incluye los siguientes pasos típicos:Toma de datos sobre la situación de partida y Análisis de la misma, Opciones funcionales y/o tecnológicas para tratamiento de los fondos documentales considerados, Diseño de aplicaciones de gestión documental (datos, textos, imágenes, sonido, vídeo, etc...) bajo un triple enfoque funcional, técnico y económico y Definición de un Proyecto global y modular en un Plan Director. (Autor)

Palabras clave: Gestión Electrónica de Documentación. Metodología. Análisis. Diseño.

\subsection{Abstract}

The sucessful implementation of Electronic Document Management Systems (EDMS) requires a previous design based on a Methodology that includes the key steps that follows: Capture of critical information and Analysis of the document situation actually, Functional and/or technological options that involve the treatment of the document fonds considered, Document management applications design (data, text, images, audio, video, etc...) under a functional, technical and economic focus, Global and modular project defined as a strategic E.D.M.S. Plan. (Author)

Keywords: Electronic Document Management. Methodology. Analysis. Design.

\section{Introducción}

En los últimos años, los Sistemas de Gestión Electrónica de Documentación (SGED) han pasado de ser un paradigma, síntesis de todas las funciones y prestaciones que teóricamente permitía desarrollar el trabajo con documentos elec- 
trónicos, a ser una realidad actuante en una minoría significativa de organizaciones dinámicas.

Lo cierto es que los SGED se han tenido que abrir camino en unos entornos informáticos bastante densos (distintas redes, sistemas operativos, bases de datos, herramientas ofimáticas, aplicaciones de gestión, etc...) lo que ha acentuado cada vez más su integración y compatibilidad con estándares de hecho, para registrar, almacenar, procesar, comunicar y recuperar objetos informativos de cualquier clase.

Por otra parte, los programas informáticos para GED están también diferenciándose de un conjunto de aplicaciones y herramientas con las que deben interactuar pero sin confundirse. En efecto, los programas GED no sustituyen a las herramientas para "Trabajo en Grupo" ni a los "Recursos Ofimáticos" pero se fructifican mutuamente.

La GED no sustituye a la "Gestión de Expedientes" ni al "Work Flow" pero incrementa enormemente su eficiencia e inicia su encauzamiento.

La GED no soluciona la "Gestión de Archivos" e integra sólo parcialmente la gestión de "Registros de Entrada/Salida", pero constituye un complemento altamente racionalizador para ambas.

La GED se perfila cada vez más como un indispensable vínculo que comunica, integra y dinamiza los distintos componentes lógicos del sistema de información de una Entidad.

\section{2. ¿Por qué centrarse en la GED en grandes Entidades?}

Obviamente porque ahí es donde ha alcanzado, de momento, mayor implantación y porque ahí es también donde su potencialidad se explícita más claramente.

En efecto, la GED resuelve infinidad de problemas cotidianos en una PYME o en un Departamento pero despliega su inmensa capacidad racionalizadora y comunicadora en grandes Entidades muy diversificadas en sus funciones, en sus líneas de actividad, con cientos de órganos en su Organigrama, con cientos y a veces miles de series documentales, con miles de tipos documentales, con redes de usuarios internos y externos distribuidas y complejas.

\section{Pautas para el análisis y diseño de Sistemas de GED}

Las pautas para el análisis y diseño de Sistemas de Gestión Electrónica de Documentación que a continuación se exponen no pretenden, obviamente, la exhaustividad, sino que constituyen un marco metodológico esquemático, sintetizado a partir del trabajo realizado en grandes Empresas y Entidades Públicas. 


\subsection{Fases de Análisis y Diseño}

Son genéricamente las siguientes:

- Toma de Datos

- Análisis y Diagnóstico de la situación de partida

- Grandes Opciones Tecnológico-Funcionales para tratamiento de los fondos documentales considerados.

- Diseño de Aplicaciones de tratamiento documental (datos, texto, imágenes, sonido, vídeo, etc) bajo un triple enfoque, funcional, técnico y económico.

- Definición de un Proyecto global y modular en un Plan Director.

\subsection{Toma de Datos}

La Toma de Datos consiste en una serie de:

- inspecciones oculares, recuentos y muestreos en los fondos documentales y archivos en cualquier soporte (papel, microfilm, magnético, óptico, etc).

- entrevistas a Usuarios y Responsables en cuanto a sus necesidades y expectativas en relación con la situación documental de partida y el SGED a implantar.

Para ello, se utilizarán los Guiones para Toma de Datos que se adaptan al caso concreto de cada Entidad.

El personal directivo y responsables técnicos de Organización, Informática, Servicios Generales, Archivo, ... facilitarán datos y opiniones respecto al SGED global a implantar y criterios generales sobre:

- Objetivos a cubrir por el Sistema y Problemas a resolver.

- Opciones tecnológicas y funcionales a adoptar para el SGED en cuanto a configuración y soportes.

- Niveles de confidencialidad y acceso a la documentación.

- Vigencia de la documentación.

- Periodos de Conservación y Lugar de Custodia de la documentación.

- Recursos Humanos y Dotaciones a adscribir al Sistema.

- Sugerencias.

En tanto que los usuarios, técnicos o administrativos que generalmente manejan los documentos, en entrevista minuciosa, facilitarán datos relacionados con las Series documentales que les afectan, del tipo:

- Funcionales y Organizativos.

- Cuantitativos.

Scire. 3 : 2 (jul.-dic. 1997) 31-43 
- Necesidades de información.

- Problemas o sugerencias, etc.

\subsection{Análisis de la Situación Documental de Partida y Diagnóstico}

Se centrará en aquellas variables y parámetros necesarios para diseño conceptual del SGED a implantar.

- Ámbito orgánico, espacial y geográfico de la Entidad, a cubrir por el SGED (toda la Entidad, uno o varios departamentos centrales, zonas o territorios, sucursales, instancias periféricas, etc.)

- Ámbito funcional o procesos de trabajo de la Entidad afectados por el SGED (funciones de almacenamiento, recuperación y gestiones varias con documentos en cada proceso): Visión de conjunto.

- Documentación e información a tratar. Se concretarán las series y los tipos documentales que se prejuzga susceptibles de digitalización o tratamiento alternativo.

- Panorama de acciones, autorizaciones, cotejos, validaciones, etc., asociados a los expedientes, dossiers o tipos documentales de cada Serie.

- Clases de documentos (alfanuméricos, imágenes, sonoros, audiovisuales, en sus respectivos soportes papel, microfilm, magnético u óptico). Especificación por grupos de series o por serie, en su caso.

- Formatos, calidad de imagen, en su caso, calidad audio y vídeo en su caso.

- Criterios de clasificación y codificación de los mismos. A nivel general de cada fondo documental y por serie o grupos de series.

- Descripción, fichas descriptivas existentes y en qué soporte.

- Tipos de búsquedas. Índices o herramientas auxiliares para la búsqueda, glosarios, thesaurus, descriptores, en su caso.

- Tablas de elementos que se consultan en la Entidad, (callejero, guías, organigrama, etc...)

- Criterios de ordenamiento topográfico y codificación de los mismos.

- Criterios en cuanto a periodos de conservación y lugar de custodia.

- Criterios generales por cada fondo y por serie o grupos de series documentales.

- Criterios en cuanto a plazos de acceso a la documentación.

- Niveles de constitución de depósitos documentales en función de su grado de actividad (activos, semiactivos, pasivos, históricos).

- Registro de Entrada / Salida existentes, mecanizados o no. 
- Red de usuarios con indicación de frecuencia y tipo de consultas, procedimientos de consulta, transferencias de documentación y otras gestiones.

- Usuarios: niveles de autorización para acceso a documentos y para funciones a desarrollar con los mismos.

- Tiempos de trabajo invertidos en tareas de explotación de la documentación: análisis, clasificación, descripción, ordenamiento, reproducción, etc., determinando las cargas de trabajo en cada tarea y los posibles "cuellos de botella" existentes.

- Especificación de series documentales con importante peso específico en consumo de tiempo de trabajo.

- Entorno informático: (arquitectura hard/soft, redes, servidores, puestos de trabajo, gestores de bases de datos...). Herramientas informáticas utilizadas para trabajo en grupo, para acceso a Internet y en la gestión documental, en su caso. Entorno ofimático disponible (proceso de textos, hoja de cálculo, base de datos, proceso de imagen, etc...).

- Volumen y superficie ocupados y destinados al fondo documental actual, en cualquier soporte.

- Prioridades fijadas por la Entidad y que condicionan la solución técnica: economía, integridad del fondo, reducción de tiempos de trabajo, espacio limitado, tiempos de respuesta a usuarios, seguridad, etc...

- Diagnóstico sobre la situación de partida. Aspectos a mantener o a modificar e innovaciones a introducir.

\section{Opciones Funcionales y Tecnológicas para Tratamiento de los Archivos considerados}

\subsection{Se formularán una o varias hipótesis de trabajo que afectan a la confi- guración del SGED en base al análisis previamente realizado}

Estas hipótesis estarán sujetas a revisión, a cada paso de avance del diseño (retroacción). Por ejemplo:

- ¿Implantar un SGED centralizado para toda la Entidad con una red de distribución de datos y documentos, en área local y/o remota?

- ¿Tomar como base un SGED departamental susceptible de ampliaciones modulares a otros Departamentos o Áreas?

- ¿Gestionar de forma centralizada en un mismo Sistema documentos de tamaño "pequeño" (A4 o A3) y planos o documentos (>A3) o bien implantar un Sistema específico para estos últimos?.

- ¿Qué series, fracciones de serie y/o tipos documentales justifican su digita- 
lización y cuales no? ¿Qué panorama de conjunto cuantitativo y cualitativo presenta la documentación a tratar?

- ¿Se justifica, previamente a la digitalización, un expurgo global de fracciones enteras de determinadas series documentales e incluso un expurgo minucioso de determinados tipos documentales o bien no resulta rentable?

- ¿Se justifica, además de la digitalización de documentos, el ampliar la descripción de parte de las series documentales o el realizar una descripción más minuciosa a nivel de expediente o documento?

- ¿Se justifica una integración de las aplicaciones informáticas de almacenamiento y recuperación de información documental en el SGED? ¿Existen o existirán aplicaciones OCR a integrar?

- ¿Se justifica el implementar una aplicación que además de las funcionalidades habituales en GED garantice la gestión de Archivos en todos sus módulos (ingresos, préstamos, expurgos, transferencias, espacio, etc.)?

- ¿Debe garantizarse la conexión lógica entre el SGED y las aplicaciones preexistentes de Gestión de Expedientes, de Registro E/S, de COLD, etc.?

- ¿Existe o va a implantarse en el futuro una aplicación informática de "Work Flow' con la que integrar el SGED?

\subsection{Opciones tecnológicas para el SGED}

En cuanto a las opciones tecnológicas para el SGED, suelen quedar acotadas en tratamiento de datos y a veces en tratamiento de imagen y sonido por el entorno informático ya implantado en la Entidad: Redes de área local o extensa, servidores de todo tipo, sistemas operativos, bases de datos corporativas, aplicaciones para trabajo en grupo, para búsquedas en Internet, etc.

Así pues, queda por definir en lo esencial la opción en cuanto a soportes documentales y sistemas en los que se utiliza cada uno de ellos.

Se considerarán aquí los cuatro tipos de soportes básicos: papel, microfilm, y especialmente los magnéticos y ópticos para documentos electrónicos.

La diversidad de soportes utilizables en un SGED es muy amplia, especialmente en lo relativo a soportes ópticos (Fig.1).

La utilización de soportes por tipo de archivo y serie documental, por grupos de series o por fracciones específicas de serie, se evaluará en función de los datos cualitativos y cuantitativos de situación de partida de la documentación y de las siguientes variables relativas a cada soporte documental:

- Densidad de almacenamiento de la documentación.

- Posibilidad de grabación única no borrable de documento terminado (edi- 
ción), de grabación única no borrable con incremento opcional de información (archivo) y de soportes borrables y regrabables.

- Perdurabilidad de la información registrada en cada soporte y en sus duplicados. Condiciones ambientales de conservación.

- Normalización de hecho y/o derecho, en cuanto a:

1. Tamaños y formatos.

2. Materiales.

3. Criterios de distribución en cada soporte de la información y control sobre la misma.

- Sistema de recuperación de documentación y de información registrada por tipo de soporte.

- Integridad de la documentación y de la información registrada que cada soporte garantiza.

- Capacidad de transmisión a distancia de documentación/información por cada soporte y sistema asociado.

- Costes de soporte y sistema asociado por:

1. Tiempos de trabajo.

2. Espacio destinado.

3. Sistemas de seguridad.

- Inversiones y Gasto anual de mantenimiento y explotación.

- Entorno legal de cada soporte:

1. Requisitos para la adjudicación de valor legal a información en cada soporte.

2. Situación actual y expectativas.

Se contemplarán especialmente soluciones basadas en la coexistencia de soportes en un sistema coherente.

\section{Diseño de Aplicaciones}

5.1. Se definirán las características esenciales de cada Aplicación de tratamiento de documentos y datos por cada serie documental o grupos de series. 


\section{DISTRIBUCIÓN DE LOS PRINCIPALES SOPORTES ÓPTICOS EN FUNCIÓN DEL MODO DE TRATAMIENTO DE INFORMACIÓN Y DEL ÁREA DE APLICACIÓN}

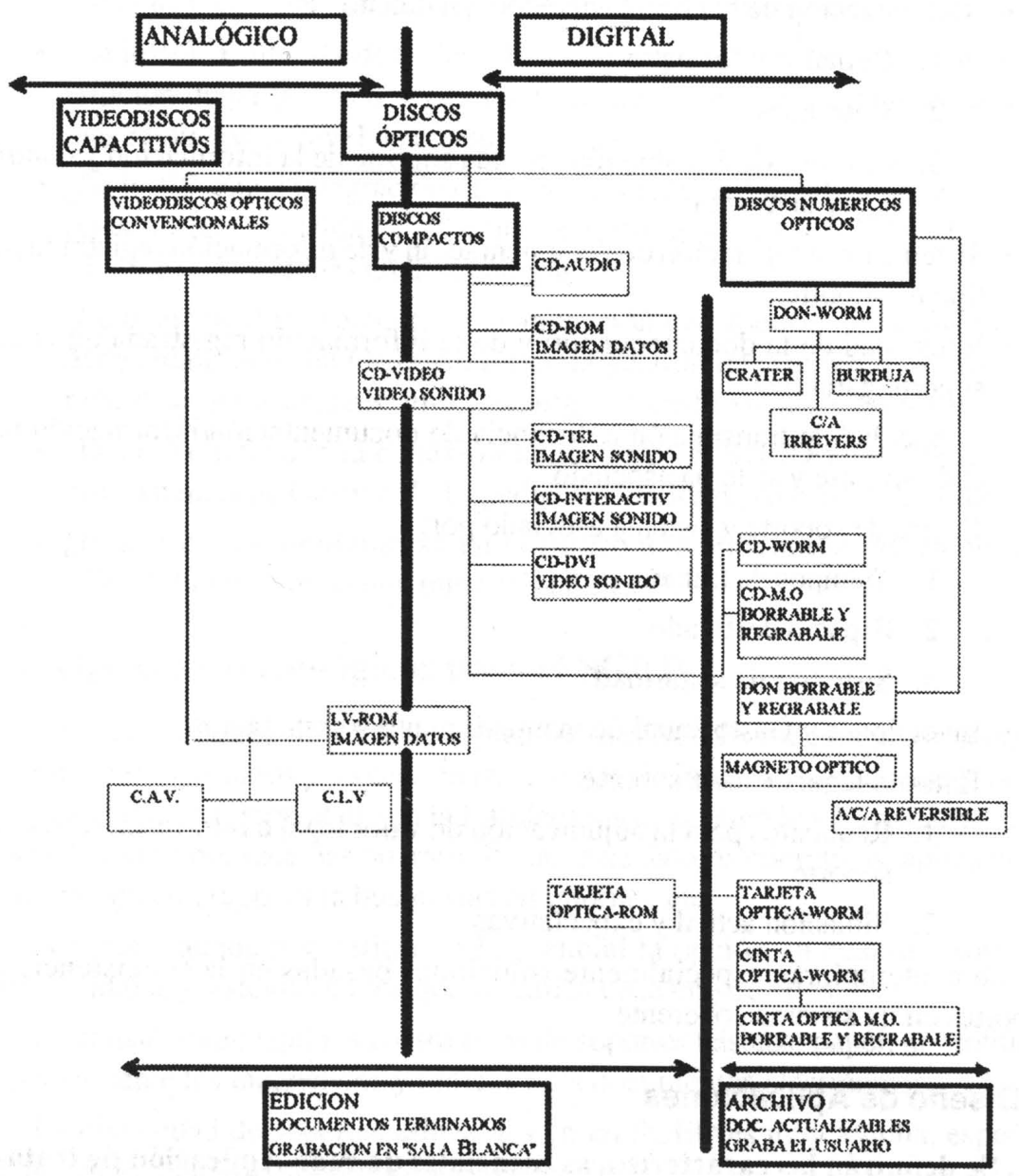

Fig.1. Distribución de los principales soportes ópticos en función del modo de tratamiento de información y del área de aplicación 


\subsubsection{Unidades documentales a gestionar}

Se debe especificar qué unidad documental generará una descripción o registro informático recuperable: expediente, dossier, documento tipo, página, etc. Se especificarán los casos en que se deban gestionar simultáneamente distintas unidades (documento, expediente, etc).

Se concretará la denominación oficial y el código de identidad de cada unidad documental.

\subsubsection{Red de usuarios:}

Se caracterizará y cuantificará la red de usuarios internos y externos, su distribución espacial y funcional.

Los Criterios de Clasificación son:

- Del más general al más específico.

- Cuadros de Clasificación, en su caso, y otros instrumentos auxiliares.

- Cantidad de documentos a tratar, especificando el número de unidades documentales y el número de páginas para el fondo documental acumulado hasta el presente y para el incremento anual de dicho fondo.Obviamente, los SGED deben ser dimensionados para poder tratar holgadamente el incremento anual de documentos y las puntas de trabajo que se produzcan (y no en función del fondo histórico acumulado que se tratará con recursos complementarios, ya sean propios de la Entidad o ajenos a la misma).

- Cantidad de documentos a expurgar física o lógicamente, según el soporte.

- Periodo de volcado de documentación en nuevo soporte. Normalmente, el incremento vegetativo se va volcando cotidianamente. Sin embargo, el tratamiento del fondo acumulado puede requerir, en función del plazo en que se programe, un redimensionamiento del Sistema o una ayuda transitoria de una Compañía de Servicios de escaneo, grabación de datos, etc... o lo que proceda.

\subsection{3. ¿Qué hacer con los documentos en papel ya digitalizados?}

En función de su valor legal, histórico u operativo, pueden ser llevados a un archivo histórico o de seguridad con bajo coste de custodia o, en su caso, destruidos. En cualquier caso, es posible un ahorro significativo de espacio y superficie, con su repercusión en costes.

\subsubsection{Grado de complejidad de la imagen documental digitalizada.}

La digitalización de imágenes implica un consumo de un número de bits/pixel ('picture element' o punto) que crece con la complejidad de aquellas: desde la imagen monocrómica sencilla (1 bit/pixel) hasta la gama de grises o 
imagen cromática de espectro total (32 a 256 bits/pixel).

- Resolución y velocidad en escáner:

1. Distinguir Sistemas que trabajan a una resolución fija (200 a 400 puntos por pulgada) de aquellos que permiten al usuario regular la resolución para cada imagen (generalmente de 50 a 800 puntos por pulgada).

2. La elección de un poder de resolución, decisivo para la calidad de imagen, aconseja hacer pruebas previas y agrupar en lo posible lotes de documentos a tratar con igual resolución.

- Ratio de Compresión:

1. Casi todos los Sistemas de Tratamiento de Imagen dicen utilizar algoritmos de compresión de datos y reducción de redundancias del C.C.I.T.T. Grupo IV ('Run Length Code', Código 'Huffman unidimensional', Código 'Read' bidimensional, etc...).

2. Un buen ratio de compresión se sitúa entre $1 / 10$ y $1 / 25$ para documentos monocrómicos no complejos digitalizados a 200 ppp, si bien puede alcanzar 1/60 con documentos sencillos.

5.1.5. Clase y número de nuevos soportes ópticos o magnéticos a utilizar para la grabación de la documentación electrónica

5.1.6. Tipo de Unidad de Almacenamiento masivo de discos ópticos ó magnéticos ("juke box", torre de lectores de CD-ROM, "'arrays de discos “")

Se diferenciarán teniendo en cuenta: tipo de soportes que admite, número de soportes, unidades de lectura o de grabación/lectura que integra, controladores, interfaces, etc.

\subsubsection{Consultas}

Se determinará:

- La frecuencia de consulta anual y en puntas de trabajo.

- Los tipos de consultas: de documentos, de páginas, de revisión de un expediente, las consultas en pantalla y/o papel, las anotaciones al documento, la necesidad de superposición de imágenes, la consulta de datos relacionados con el documento o de la referencia descriptiva del mismo, etc...

5.1.8. Estimación de coste de cada aplicación por:

- Tratamiento de imagen documental y tratamiento audiovisual, en su caso.

- Análisis y descripción documental, en su caso, y grabación de datos. 


\subsection{Requisitos del SGED exigidos por la Aplicación}

El Diseño de Aplicaciones permite suministrar algunos puntos de referencia útiles para definir requisitos funcionales y técnicos del SGED a implantar:

- Acceso a Red de Área Local y Comunicaciones. Carga de datos, imágenes o información audiovisual a soportar por las redes.

- Configuración y requisitos planteados por el funcionamiento del SGED.

- Caracterización de puestos de trabajo.

- Los terminales imagen de tipo pantalla (tamaño, resolución, etc.).

- Los terminales imagen de tipo impresora (tamaño, resolución, velocidad, etc.).

- Los periféricos para información audiovisual (cámaras, micrófonos, proyectores, altavoces, pantallas, etc.).

- Tiempos de trabajo/año y cargas del SGED.

Se debe concretar al número de unidades documentales a tratar y el tiempo de trabajo orientativo para las siguientes tareas:

- análisis, descripción y codificación de documentos.

- indización de documentos en ordenador.

- escaneo o tratamiento audio/vídeo en su caso, control de calidad y validación de indización.

- búsquedas y actualización de documentos.

- expurgos lógicos y físicos a realizar.

- administración y gestión general de bases de datos y de documentos.

- otras tareas.

Se calculará así el tiempo total anual de explotación y mantenimiento del SGED lo que permitirá estimar los recursos humanos necesarios.

\subsubsection{Superficie y espacio a destinar al SGED}

5.2.2. Consideraciones sobre el Software de Aplicación del SGED en gestión de datos y de documentos

Una especificación de todas las funcionalidades que debería tener un buen software GED requeriría por sí sola todo el espacio de esta ponencia. Cabe men cionar que debe cubrir los requisitos derivados del análisis y diseño anteriores y, especialmente, debe considerarse al menos si:

- ¿Está la Aplicación basada en estándares del mercado o es una aplicación "propietaria"? 
- ¿Es fácil de integrar con el entorno informático de la Entidad: sistemas operativos, redes, comunicaciones, aplicación de trabajo en grupo, base de datos corporativa, etc.?

- ¿Es fácil de integrar con la gestión de Registros E/S, con la gestión de Archivos, con la gestión de Expedientes y con las demás Aplicaciones de gestión? ¿Permite acceder a Internet?

- ¿Soporta objetos de todo tipo: imágenes, datos y textos alfanuméricos, vídeo, sonido?

- ¿Dispone de un generador de tantas fichas descriptivas (bases de datos) como se necesiten?

- ¿Dispone de recursos de búsqueda potentes y permite combinar argumentos de búsqueda relacionales y documentales?

- ¿Permite visualizar e imprimir sin llamar a la aplicación?

- ¿Permite controlar versiones y actualización de documentos?

- ¿Dispone de una gestión de usuarios potente con funciones y niveles de autorización, búsquedas por perfiles y predefinidas por usuario, etc...?

- ¿Dispone de herramientas de desarrollo adecuadas y potentes?

\subsubsection{Referencias sobre aspectos cualitativos del SGED:}

- Seguridad y confidencialidad.

- Integridad de la documentación.

- Perdurabilidad de la información grabada.

- Margen de error en la grabación.

- Trabajo en ambiente normal de oficina.

- Eficacia en búsquedas.

- Rentabilidad funcional.

- Pertinencia en las búsquedas.

- Seguridad.

- Confidencialidad.

- Condiciones de legalidad.

- Evaluación económica del sistema a implantar, considerando al menos los siguientes conceptos:

- Inversión a realizar en el SGED y en tratamiento documental:

1. Subsistema de datos

2. Subsistema de documentos 
3. Integración con aplicaciones y entorno informáticos

4. Tiempo a invertir en Implantación y Puesta en Marcha (descripción, indización, escaneo o tratamiento audiovisual, pruebas, formación, etc.)

5. Otros conceptos

6. Comparación de Gasto Anual entre el sistema actual y sistema nuevo, en cuanto a tiempos de trabajo (Personal), superficie destinada, seguridad, consumibles, mantenimiento, etc.

- Cálculo del "Rendimiento del Capital" a invertir o del "Tiempo de retorno" de la Inversión.

\section{Plan Director de Puesta en Marcha}

Se concretará por cada Serie a tratar:

- Período global de Puesta en Marcha a corto / medio plazo (3 a 5 años) del nuevo Sistema y camino crítico a seguir en la implantación de cada módulo del nuevo SGED, de todas sus funcionalidades y en el tratamiento de documentos y datos a cargar en el mismo.

- Definición de Fases de Puesta en Marcha y por cada Fase:

1. Tareas a realizar.

2. Carga de datos y/o documentos a tratar por cada tarea.

3. Recursos humanos y técnicos por tarea.

4. Tiempos de trabajo y plazos por tarea.

5. Inversión a realizar en cada fase y evaluación del gasto anual. 